\title{
Requirements engineering for User-centered school food ordering system
}

\author{
Diyana Binti Halim Khoo', Afdallyna Fathiyah Harun², Saiful Izwan Suliman ${ }^{3}$ \\ ${ }^{1}$ MSc IT Student, Faculty of Computer and Mathematical Sciences, Universiti Teknologi MARA, Malaysia \\ ${ }^{2}$ Faculty of Computer and Mathematical Sciences, Universiti Teknologi MARA, Malaysia \\ ${ }^{3}$ Faculty of Electrical Engineering, Universiti Teknologi MARA, Malaysia
}

\begin{tabular}{l} 
Article Info \\
\hline Article history: \\
Received Apr 26, 2019 \\
Revised Jun 28, 2019 \\
Accepted Jul 10, 2019 \\
\hline
\end{tabular}

\section{Keywords:}

Heuristic evaluation

Heuristics

Human computer interaction

Usability

User-centered design

\begin{abstract}
Understanding user requirement for a technology design is central to user experience. A user-centered technology design should consider user needs and constraints as well as abide to the principles of HCI design heuristics. This paper describes the requirements gathering for Kantin Online System, a school food ordering system where we considered the needs and constraints of different stakeholders involved and elicit a compromise where the needs of all parties can be met. We then applied usability heuristics into the system design to facilitate perceived ease of use and perceived usefulness. We conclude this paper with experts' evaluations towards the heuristic elements of the system design concept and possible future work.
\end{abstract}

Copyright $(2020$ Institute of Advanced Engineering and Science. All rights reserved.

\section{Corresponding Author:}

Afdallyna Fathiyah Harun, Faculty of Computer and Mathematical Science, Universiti Teknologi MARA, 40450 Shah Alam, Malaysia.

Email: afdallyna@tmsk.uitm.edu.my

\section{INTRODUCTION}

Ease of use and usefulness are core concepts in usability as it determines the acceptance, adoption and use of a technology [1-2]. The key to this is comprehensive user understanding that entails their mental model [3-4] on how they would operate a technology as well as their expectation on how the system would meet their functional needs. Human Computer Interaction is a domain in Computer Sciences that very much stresses on technology usability as it posits how a technology can be used effectively and efficiently by users in achieving specific goals in a specified context of use and ultimately users feeling satisfied when and after interacting with the technology [5-7] .

There are various usability models available for reference that helps determine the attributes that an artefact should have for user to perceive the artefact as effective, efficient and satisfying to use. Some examples include Eason Model, Shackel's Model, ISO9241-11, ISO/IEC 9126 and Nielsen's Usability Heuristics (see [8-15]) with the latter being the most predominantly referred to for system interface design and system evaluation.

With the continuing growth of web systems and mobile applications, users are presented with abundance of choices. Therefore, any artefact design must be tailored to meet user needs and their context of use in a designated environment [16] to ensure user acceptance. This could be done by incorporating usability evaluation activities into the development and evaluation stage [17-19]. One such example is school food purchasing system.

A school food purchasing system generally involves information seeking, product categories, pricing and product selection processes. However, the stakeholders would involve parents, school canteen 
operator as well as children. Therefore, effort must be undertaken to capture relevant user behavior as well as relate them to HCI principles. This is because the latter encapsulates not only design expectations that meet typical user behavior but also how design can be adopted to influence user adoption of a product and in turn affect the depth of interactivity with the product [20].

Many parents in Malaysia are obligated with work commitments from $8 \mathrm{am}$ to 5pm daily, which unfortunately limit their chances to prepare fresh cooked food for their school-going children. Malaysian children spend most of their time at school from $7: 30 \mathrm{am}$ to $1: 30 \mathrm{pm}$, or $1: 30 \mathrm{pm}$ to $6: 30 \mathrm{pm}$ or $8: 00 \mathrm{am}$ to $3: 30 \mathrm{pm}$ (the timing depends on term year as well as operational structure) and therefore rely on school canteen food for their brunch, lunch and tea-time. Children who do bring home-cooked food would be provided with lesser nutritional value if compared to freshly served food [21]. Parents whose children buy food from the canteen find themselves complaining over the quality and portion of the food to the food price [22-23]. Moreover, children simply buy food they find appealing with little regard on the nutritional value which is why they are always consuming processed food. Children therefore appear at the losing end as the lack of nutritional food can affect their social skills and reading development [24].

Findings from [25] suggests that both parents and canteen operator can play a role in children's food choices in school. Parents would be able to participate in influencing their child's healthy eating lifestyle by making informed decisions on food purchase. Canteen operators would then be compelled to provide healthy and nutritious food to the children as a delivery of services that is expected of parents.

Providing parents with a tool to manage their child's diet via menu selection, nutritional intake monitoring and controlled budget is definitely an added value to everybody; (i) children would consume healthy food, (ii) parents can be certain of proper food intake, (iii) canteen providers could manage their food preparation, and (iv) school would have healthy students ready for the daily lessons.

\subsection{Requirements Engineering}

Requirement engineering is the engineering discipline of establishing user requirements and specifying software systems [26]. It mainly involves the processes of gathering requirements from the users or stakeholders in accordance with their needs and demand towards the proposed system. Its key concept is "designing the right thing" rather than "designing the thing right" [27]. Requirements engineering is without a doubt a critical phase as it includes requirement management and planning, data collection from all the stakeholders, requirement analysis of data, requirement engineering documentation and modelling, validation and verification of the requirement [28].

A good requirement engineering exercise for a system development would assist in designing a quality user interface [29] that meets user needs. This is because, the process encapsulates understanding user's mental model (i.e. how they perceive the use of system) as well as increasing the probability for system acceptance [30]. However, this needs to be done before system release to ensure any design issues could be addressed before hand [31]. This requires an iterative process as designing a good user interface is not a straightforward process [32].

As part of the requirements engineering process, we have interpreted user needs into a set of design which employs heuristic principles. Additionally, we have evaluated the end-product based on a Nielsen's list of heuristic principles [12] which is considered standard within the domain of Human Computer Interaction. In a heuristic evaluation, usability experts will inspect the system's interface and see how well it meets the heuristic principles. They are responsible in identifying potential usability issues and make recommendations on how to improve them [12].

In this paper, we intend to describe how we produced the Kantin Online System (English equivalent: Canteen Online System) which aims to allow parents to purchase their children's school meal through advanced booking. We will describe the user requirement data gathering process, the prototype design as well as expert evaluation on the prototype design.

\section{METHODS}

Figure 1 illustrates the processes of requirement engineering applied by our study. The overall idea of the framework is to fulfil elicitation of user requirements from the relevant stakeholders, design and develop the system as well as to evaluate the final product based on heuristic principles. The framework attempts to employ the user-centred element which is core in developing a usable and useful system design [15] while remaining within a scientific procedure of fact collection and analysis. The description of the tasks can be found in the proceeding sections. 


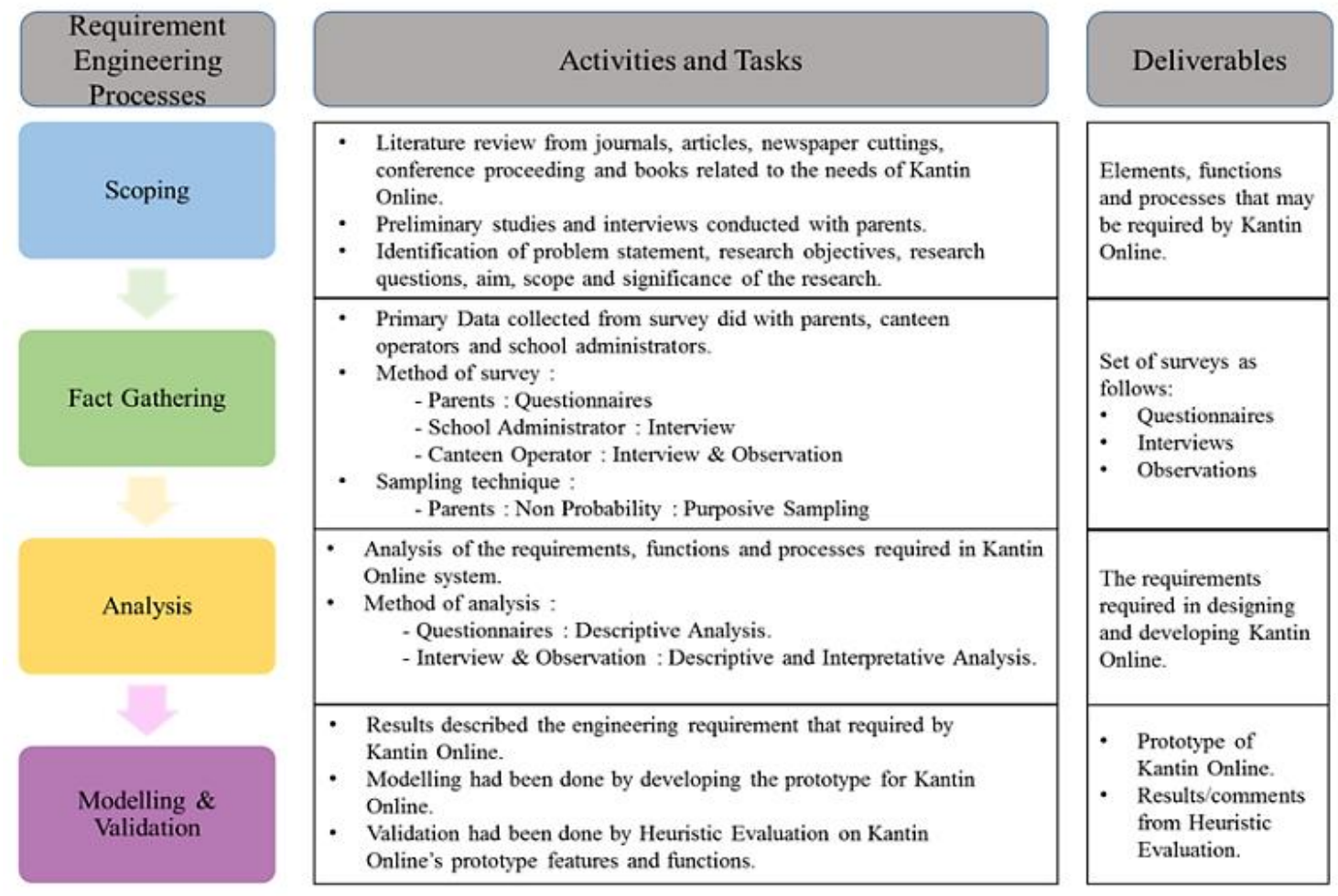

Figure 1. Requirement Engineering Framework for Kantin Online System

\subsection{Data Gathering}

Our data gathering process took place at Sekolah Kebangsaan Seksyen 27(2), a primary school in the city of Shah Alam, Selangor, Malaysia. We targeted parents with primary school-going children within the urban area as we feel they are at the better position to purchase food in advance (via food booking system) due to the costing involved. Additionally, we wanted to have a better understanding of their underlying issues, their needs and wants in regard to food purchase and food intake of their children in school. A set of 30 questions via an online questionnaire were sent to 121 parents. The questionnaire contained four sections; (i) demographic details, (ii) current perception on school canteen, (iii) preferred features for Kantin Online and (iv) menu choices and preferred budget.

We also interviewed school canteen operators to understand their business logic and strategy. As much as we wish to design a system that meets parents' needs, the constraints of the service provider must also be considered. For example, the capability of the canteen to provide nutritious food within parents' desired budget or the ability of the canteen to provide the food. This is important as the main intention of Kantin Online system is to provide healthy menu with enough quantity and affordable price for parents to purchase for their children

\subsection{Data Analysis, Modeling and Validation}

Descriptive and interpretative analysis were done on the collected data as part of the requirement engineering for Kantin Online system. The requirements from both stakeholders were presented to them in sketched forms (lo-fidelity prototype) to confirm their system needs. Some refinements were made to the design which we then proceeded to middle fidelity prototyping using Bootstrap v3.3.6. software. The prototype was also used to validate the designed functionality. However, it must be acknowledged that the prototype was simply a middle-fidelity version hence not fully functional.

Heuristic Evaluation [12] was employed for the prototype evaluation. It underlines ten principles in system which is summarized in Table 1. 


\section{RESULTS AND ANALYSIS}

\subsection{User Requirement}

121 parents comprising 44 fathers, 70 mothers and 7 guardians responded to the survey. The respondents were aged between 25 to 50 years old with 30 to 39 years of age being the group majority. From all the respondents, $76 \%$ of them have children buying food from the school canteen daily.

For the canteen menu, parents expect wide range of quality food choices as well as served in appropriate quantity suitable with children food intake as well as within affordable price range (a budget of RM60/month). However, at present, the service provided by the canteen did not meet their expectations as children are often served with unhealthy food such as nuggets, sausages and fries. Also, they found the food to be rather expensive and limited in option. Parents have expressed desire to be more in control on the food purchased and consumed by their children at school. The Ministry of Health Malaysia had stated that children aged 7 to 9 years old need to have $1800 \mathrm{kcal}$ to $1600 \mathrm{kcal}$ daily [21]. Not knowing the food consumed by their children at school would impede parents from discovering the calorie amount consumed by their children that day. This in turn may result in children getting more or less amount of the daily recommended calorie intake due to the food taken at home for the rest of the day.

From the requirements gathering process, it was determined that features parents require for the Kantin Online system are variety of menu option, nutrition calculator, list of allergens in each menu, ability to purchase food in advance (food booking) as well as payment gateway. The key idea is to allow their children to eat different type of healthy and food daily which is safe while not breaking the bank. We then matched these requirements to the constraints of the canteen operator. The system design should allow canteen operators to measure the actual supply and demand for their operations as this would allow them to be cost effective as well as avoid wastage. Based on our interviews with them, we learned that they buy raw materials in advance based on what they plan to sell for the week. Food wastage typically happens on unsold food. Following this, they agree that the feature allowing food booking in advance would benefit them as they could better plan the purchase of raw materials as well as able to estimate the quantity of food to prepare which would help avoid food wastage.

Table 1. Attributes of Usability Heuristics (Adapted from [12])

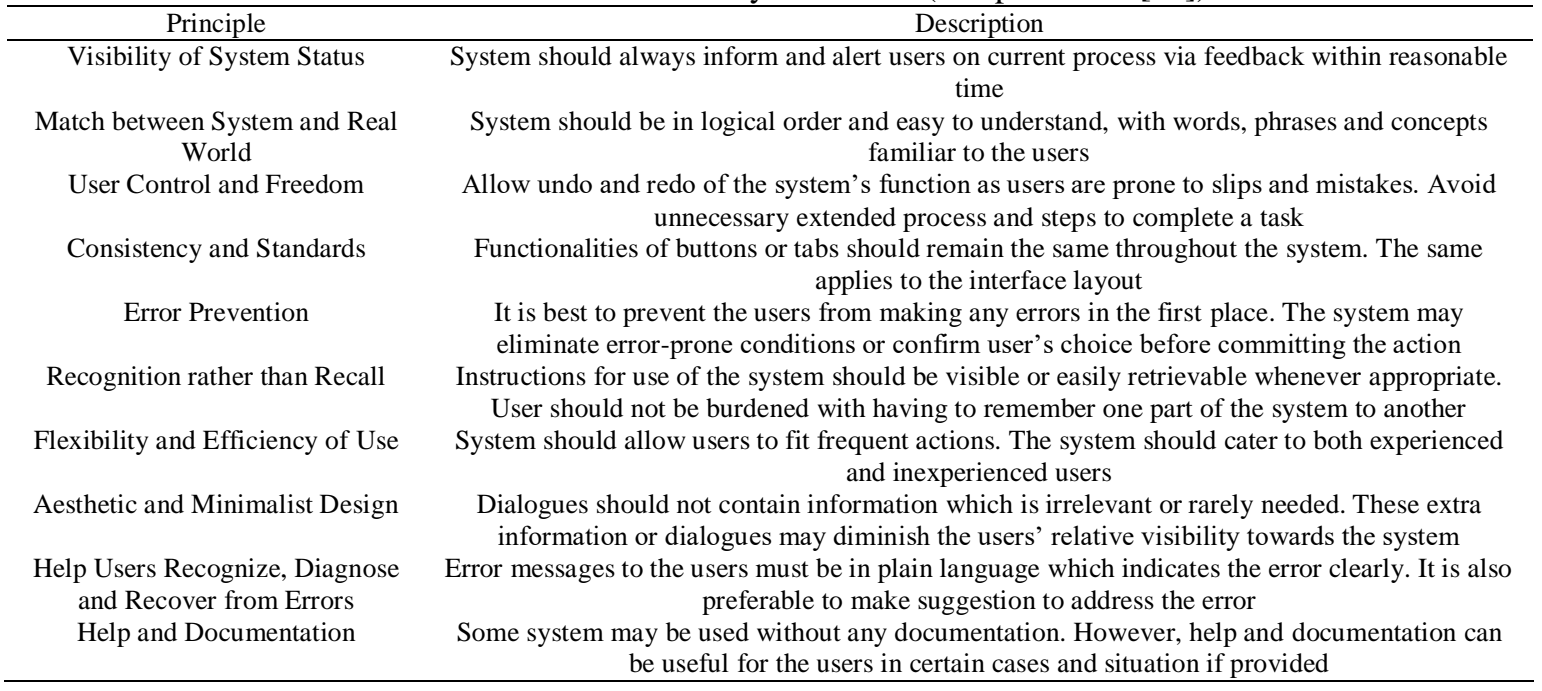

\subsection{Prototype Development - Parents Module}

Figures 2 and 3 show some of the screen grab of the Kantin Online system. Parents are provided with different menu options for main course, desserts, drinks and snacks which they can click "Add to Cart" when making the selection for their children. Food purchase can only be done on a weekly basis. Once "Add to Cart" has been clicked, a prompt will appear providing further details such as allergens, calorie count as well as desired day of the week to serve the food to their child. Upon completion, parents can proceed to make payment by clicking "Checkout". Here, an order summary will be displayed, together with payment options (credit card, bank transfer, PayPal) as well as billing address.

The purchased food menu will then be tabulated as a list in "My Order List" module. In this module, it will display date of food to be redeemed, food purchased, price and coupon printing button. The latter was 
included so children could present it to the canteen operator as proof of purchase and to redeem their purchased food. The food order list for each child were listed according to the date of food to be redeemed.

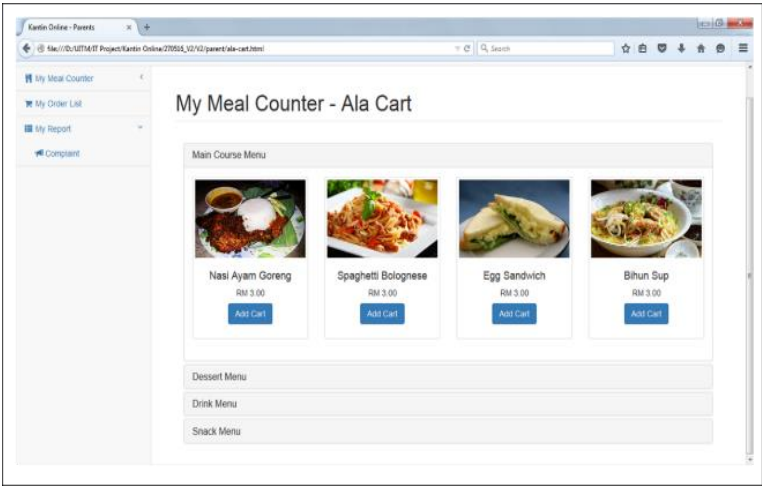

Figure 2. Screen Grab for Menu Module

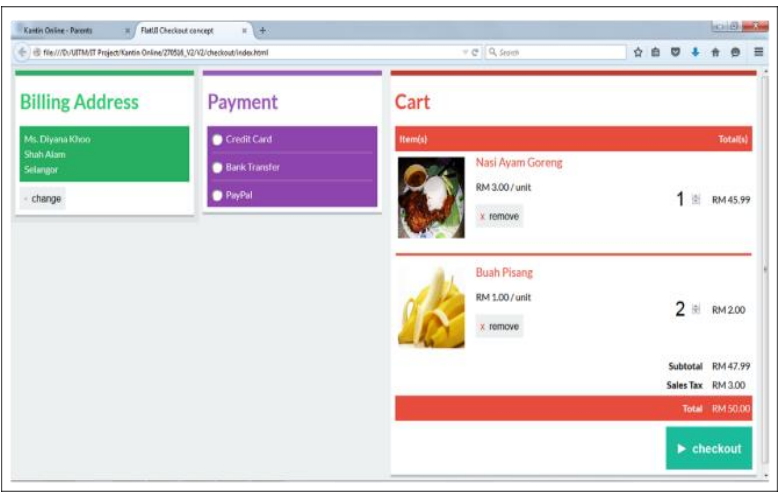

Figure 3. Screen Grab for Order Summary

\subsection{Prototype Development - Canteen Operator's Module}

The school canteen operator is provided with "Menu Management" module that allows them to input menu details such as food image, menu name, price, calories and list of possible allergens as per menu approved during the business tendering process with the school management. In the previous section it was mentioned that parents can only make purchase a week in advance. Hence, canteen operator can create different menu per week allowing more options throughout the month. This helps avoid menu repetition, more manageable purchasing of raw materials as well as optimal food preparation.

Other features made available also include (i) Sales Report - daily sales report which include quantity for each food sold, total sales of the day/week/month which will ease the task of the canteen operator for its supply chain management as well as its profits and revenue projection, (ii) Student Orders provide a list of menu booked in advance by each student for the week that helps them confirm the menu that needs to be prepared in the canteen.

\subsection{Heuristic Evaluation}

We invited two HCI experts to evaluate the Kantin Online System based on Nielsen's Usability Heuristics as shown in Table 1. The evaluation is significant in the identification of design flaws to better improve its usability in ensuring that the end product would be useful and usable by the stakeholders.

\subsubsection{Visibility of System Status}

Experts found that that the system has good visibility. Prompts are generated to confirm user's action before committing it allowing users to avoid unnecessary or critical errors.

\subsubsection{Match between System and Real World}

The experts emphasized the need for the system to have logical order and to "speak" users" language. As Kantin Online focused on the purchasing of healthy menu, they have advised for us to revise the wordings of the menu tab into "Healthy Main Course" and "Healthy Drinks" as opposed to the original "Main Course" and "Drinks". The experts also found the labelling for "Dessert" tab confusing when the menu options there were just fruits. Hence, they have suggested to revise the menu label into "Healthy Fruits". Similar feedback was also given for our "Snacks" menu tab as the menu list were just traditional Malaysian soft cakes (i.e. Traditional Kuih). They advised the label to be changed to "Kuih" instead. Although the terminology here is in the Malay language, they attested that this is acceptable as the stakeholders understood Malay and more importantly, would not confuse users when making their selection. Figure 4 illustrates this design problem. 


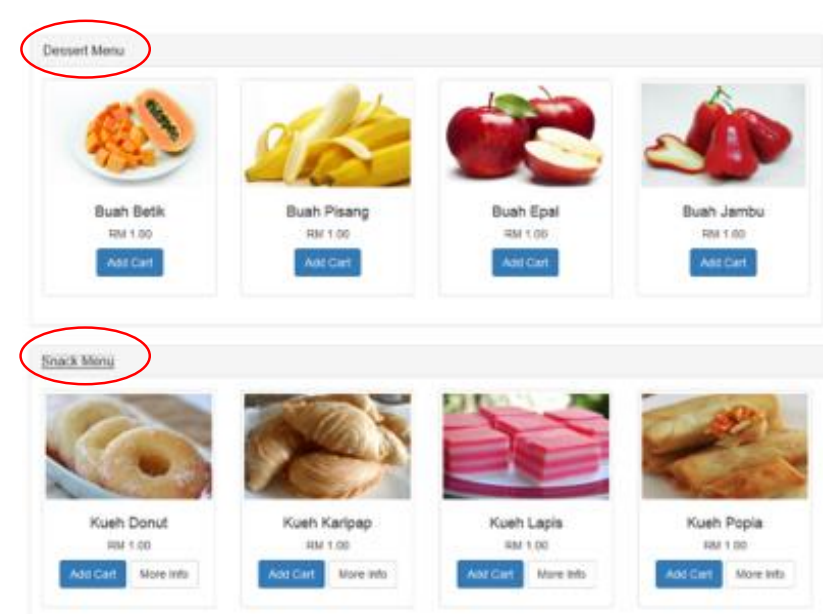

Figure 4. Problematic Wordings that could Affect Users' Understanding of Functionality

\subsubsection{User Control and Freedom}

Our design did not meet this heuristic as experts claimed we did not provide features that allow users to easily go to the main page (i.e. Home button) or to undo user's previous action (i.e. back button). In our defense, we prioritized on other heuristics to highlight the system's main objective (i.e. menu management by the canteen operator and menu booking by the parents). Nevertheless, the experts have cautioned us to apply this heuristic as we further refine the prototype into a complete system.

\subsubsection{Consistency and Standards}

The experts commended that our system met this heuristic well. This is because the interface layout, placement of the buttons and the wordings remained consistent throughout the system. Moreover, the flow of the features also follows a logical order reflecting user's mental model which in turn would provide better usability of the system [33]

\subsubsection{Error Prevention}

We did not apply this heuristic into the design. The experts have advised for us to refine the design by including input constraints on the input field particularly in input fields which requires numbers. The input field should suggest the preferred input type for number fields, the number of digits required as well as declining users input should characters inserted are not number type.

\subsubsection{Flexibility and Efficiency of Use}

In our initial design, parents can view their menu selection at the "Order Summary" module. This means as parents make their menu choices for upcoming days of the week in the "My Meal Counter" module, parents would have to separately browse the "Order Summary" module should they want check their previous food order. Following this, the experts suggested that the "Order Summary" page be provided adjacent to the "My Manual Counter" page, where it will appear on the left pane of the page upon user request. This simple design improvement would make the system more flexible and efficient to use.

\subsubsection{Recognition Rather than Recall}

The experts had commented that this heuristic is further supported by the heuristic of flexibility and efficiency of use which had been explained earlier. They have suggested that the selected menu tab should always remain visible as to assist users in being aware of which module users are currently at. We did not do this in the initial design.

\subsubsection{Aesthetic and Minimalist Design}

The experts did comment on the layout and the use of colours in the prototype. Currently the prototype used white background without any decoration, and this may not excite users to use the system. Thus, the experts suggested the use of more interesting colours and to make sure that the system does not look dull which could bore users over time. Alternative arrangement of the buttons, images and functions could also be considered as to make it further exciting to use. 


\subsubsection{Help Users Recognize, Diagnose and Recover from Error}

Error prevention message was not created in this prototype as we focused on the functionality process. The experts advised that error messages are very important and should be incorporated into the system design.

\subsubsection{Help and Documentation}

We too did not provide this feature as it was intended from the very beginning that system evaluation will be done by the experts and not users. We believe that such feature is significant if users themselves explore the system and they could refer to it should they face difficulties or errors in using the system. Nevertheless, the experts emphasized on the need of this feature as to assist users to better use the system.

\section{CONCLUSION}

The purpose of this study was to produce requirement engineering of a system called Kantin Online. This system could serve as a medium of engagement amongst parents and canteen operators in managing children's healthy food purchase and preparation. From the preliminary studies conducted with the stakeholders, we learned that parents prefer better control on their children's food intake at school canteen while the canteen operators would like to better manage their resources in preparing the food for the children. Both stakeholders have their preferred feature which we have determined through the requirements gathering process (via interview, questionnaire and observation).

A middle fidelity prototype was developed with the features that support user needs as well as applying Nielsen's Usability Heuristics into the system design. The prototype was presented to two HCI experts which generally finds the system usable and has good usability. However, they attested the need to address some of the heuristic principles to ensure that the final system would be better accepted by the stakeholders.

Here therein lies the problem - a presented prototype is sometimes perceived as fully functional and experts would evaluate the system design from all perspectives of heuristic principles. Although this presents a benefit for designers to uncover design problems, it also presented a problem where experts may lose sight on the main intention of the system evaluation - to see if the system design is able to support the main functionality. Moreover, as the prototype is at its iteration phase, some heuristic principles can be added later after confirming more critical functions. Following this, we would suggest that designers also keep experts at tabs by only highlighting the heuristics they have applied in the design as well as casually reminding the experts on the objectives of the evaluation.

Requirements Engineering process have proven to be beneficial in the development of a usable system. The user-centered design which consider user needs, sketching design to visualize system concept as well constructing a prototype which could be used for evaluation helps confirm that requirements are met. However, a usable system can only be achieved if the interface design considers heuristic principles from the very beginning. This is because Nielsen's Usability Heuristics [12] embodies user behavior and expectations when interacting with a system.

\section{ACKNOWLEDGEMENTS}

The authors would like to express the gratitude to the Ministry of Higher Education, Malaysia and Universiti Teknologi MARA, Selangor, Malaysia for the financial support given for this project (BESTARI Grant) [File No: 600-IRMI/PERDANA 5/3 BESTARI (095/2018)].

\section{REFERENCES}

[1] Deraman AB, Salman FA. Managing usability evaluation practices in agile development environments. International Journal of Electrical and Computer Engineering. 2019 Apr 1;9(2):1288.

[2] Wahyuningrum T, Mustofa K. A Systematic Mapping Review of Software Quality Measurement: Research Trends, Model, and Method. International Journal of Electrical \& Computer Engineering (2088-8708). 2017 Oct 1;7(5).

[3] Mayr E, Schreder G, Smuc M, Windhager F. Looking at the representations in our mind: Measuring mental models of information visualizations. In Proceedings of the Sixth Workshop on Beyond Time and Errors on Novel Evaluation Methods for Visualization 2016 Oct 24 (pp. 96-103). ACM.

[4] Liljestrand I, Gonzales M, Shin D. Developing a mental model for use in the context of computer security. In Proceedings of the 34th ACM/SIGAPP Symposium on Applied Computing 2019 Apr 8 (pp. 2336-2339). ACM.

[5] Cho YC, Sagynov E. Exploring factors that affect usefulness, ease of use, trust, and purchase intention in the online environment. International Journal of Management \& Information Systems (IJMIS). 2015 Jan 22; 19(1):21-36. 
[6] Larusdottir MK, Bjarnadottir ER, Gulliksen J. The focus on usability in testing practices in industry. InIFIP Human-Computer Interaction Symposium 2010 Sep 20 (pp. 98-109). Springer, Berlin, Heidelberg.

[7] Gu H, Hou W, Qin X, Zhang L, Dai Y. The Effects of Aesthetics in Usability Testing for B2C E-commerce Websites. InProceedings of the Fourth International Symposium on Chinese CHI 2016 May 8 (p. 2). ACM.

[8] Eason KD. Towards the experimental study of usability. Behaviour \& Information Technology. 1984 Apr 1;3(2):133-43.

[9] Shackel B. Ergonomics in design for usability. InProceedings of the Second Conference of the British Computer Society, human computer interaction specialist group on People and computers: designing for usability 1986 Dec 1 (pp. 44-64). Cambridge University Press.

[10] ISO 9241. (1998): Ergonomics requirements for office work with visual display terminals (VDTs) - Part 11: Guidance on usability.

[11] ISO/IEC 9126 (1991) Software product evaluation - Quality characteristics and guidelines for their use

[12] Nielsen J. Enhancing the explanatory power of usability heuristics. InProceedings of the SIGCHI conference on Human Factors in Computing Systems 1994 Apr 24 (pp. 152-158). ACM.

[13] Salvendy G, editor. Handbook of human factors and ergonomics. John Wiley \& Sons; 2012 May 24.

[14] Jordan PW, Thomas B, McClelland IL, Weerdmeester B, editors. Usability evaluation in industry. CRC Press; 2014 Jul 22.

[15] Shackel B. Usability-context, framework, definition, design and evaluation. Interacting with computers. 2009 Dec 1;21(5-6):339-46.

[16] Hornbæk K, Hertzum M. Technology acceptance and user experience: A review of the experiential component in HCI. ACM Transactions on Computer-Human Interaction (TOCHI). 2017 Nov 13;24(5):33.

[17] da Silva TS, Silveira MS, Maurer F. Usability evaluation practices within agile development. In2015 48th Hawaii International Conference on System Sciences 2015 Jan 5 (pp. 5133-5142). IEEE.

[18] Bevan N. Extending quality in use to provide a framework for usability measurement. InInternational Conference on Human Centered Design 2009 Jul 19 (pp. 13-22). Springer, Berlin, Heidelberg.

[19] Bornoe N, Stage J. Usability engineering in the wild: How do practitioners integrate usability engineering in software development?. InInternational Conference on Human-Centred Software Engineering 2014 Sep 16 (pp. 199-216). Springer, Berlin, Heidelberg.

[20] Köhler CF, Rohm AJ, de Ruyter K, Wetzels M. Return on interactivity: The impact of online agents on newcomer adjustment. Journal of Marketing. 2011 Mar;75(2):93-108.

[21] Mazuki MN, Keracunan Makanan. Retrieved from My HEALTH Kementerian Kesihatan Malaysia: http://www.myhealth.gov.my/index.php/pemakanan/keselamatan-a-kualiti-makanan/keracunan-makanan, 2014

[22] Idris SM. Elakkan Makanan Kantin Yang Tidak Sihat. Retrieved from MalaysiaKini: http://www.malaysiakini.com/letters/145723, 2014

[23] H, Guru Turut Terkesan Harga Mahal. Retrieved from Sinar Harian: http://www.sinarharian.com.my/edisi/selangor-kl/guru-turut-terkesan-harga-mahal-1.473525, 2016

[24] Jyoti DF, Frongillo EA, Jones SJ. Food insecurity affects school children's academic performance, weight gain, and social skills. The Journal of nutrition. 2005 Dec 1;135(12):2831-9.

[25] Dick M, Lee A, Bright M, Turner K, Edwards R, Dawson J, Miller J. Evaluation of implementation of a healthy food and drink supply strategy throughout the whole school environment in Queensland state schools, Australia. European journal of clinical nutrition. 2012 Oct;66(10):1124.

[26] ur Rehman T, Khan MN, Riaz N. Analysis of requirement engineering processes, tools/techniques and methodologies. International Journal of Information Technology and Computer Science (IJITCS). 2013 Feb;5(3):40

[27] Boehm BW. Software engineering economics. IEEE transactions on Software Engineering. 1984 Jan(1):4-21.

[28] Pandey D, Suman U, Ramani AK. An effective requirement engineering process model for software development and requirements management. In 2010 International Conference on Advances in Recent Technologies in Communication and Computing 2010 Oct 16 (pp. 287-291). IEEE.

[29] Sowunmi OY, Misra S. An empirical evaluation of software quality assurance practices and challenges in a developing country. In2015 IEEE International Conference on Computer and Information Technology; Ubiquitous Computing and Communications; Dependable, Autonomic and Secure Computing; Pervasive Intelligence and Computing 2015 Oct 26 (pp. 867-871). IEEE.

[30] Abdullah N, Abdul Hamid AF. Interface design features of mobile application for senior citizens. International Journal of Electrical and Computer Engineering. 2019 Apr 1:9(2)

[31] Javed A, Maqsood M, Qazi KA, Shah KA. How to improve software quality assurance in developing countries. Advanced Computing. 2012 Mar 1;3(2):17.

[32] Tidwell J. Designing interfaces: Patterns for effective interaction design. "O'Reilly Media, Inc."; 2010 Dec 15.

[33] Esser P. Embrace the Mental Models of Users by Implementing Tabs. Retrieved from Interaction Design Foundation: https://www.interaction-design.org/literature/article/embrace-the-mental-models-of-users-byimplementing-tabs, 2019. 